\title{
Correlação Clínico-Radiográfica
}

\section{Caso 6/2002 - Instituto do Coração do Hospital das Clínicas da FMUSP}

\author{
Edmar Atik
}

São Paulo, SP

Dados clínicos - Criança do sexo masculino, com seis anos de idade, operada no primeiro mês de vida a fím de diminuir o tamanho do átrio direito e a repercussão da insuficiência tricúspide em diagnóstico de aneurisma idiopático do átrio direito. Há um ano, vinha referindo cansaço a médios esforços. Ao exame físico, notava-se discreta cianose (saturação arterial de 02 de $90 \%$ ), eupnéico e pulsos arrítmicos por muitas extra-sístoles. Pesava $24 \mathrm{~kg}$ com altura de $120 \mathrm{~cm}$. A pressão arterial era de 100/60mmHg e a freqüência cardíaca de $93 \mathrm{bpm}$. Turgência jugular era nítida a $25^{\circ}$. No precórdio, havia impulsões sistólicas discretas nas bordas esternais, direita e esquerda. As bulhas eram normofonéticas e auscultava-se sopro sistólico de ejeção, discreto no $3^{\circ}, 4^{\circ} \mathrm{e}$ $5^{\circ}$ espaço intercostais. O fígado era dolorido e palpado a $3 \mathrm{~cm}$ do rebordo costal direito. O eletrocardiograma de $24 \mathrm{~h}$ mostrava que $60 \%$ dos batimentos cardíacos eram decorrentes de extra-sístoles supraventriculares. Havia sinais de sobrecarga diastólica discreta de ventrículo direito com morfologia rr'em V1 e qRs em V6, atraso na condução final ventricular e onda T negativa de V1 a V3. A onda P não era alterada quanto à morfologia e à voltagem. SÂP localizava-se $\mathrm{a}$ $+10^{\circ}, \mathrm{SÂQRSa}+80^{\circ} \mathrm{eSÂT} \mathrm{a}+30^{\circ}$.

Imagem radiográfica - Apresenta forma cardíaca inusitada com grande aumento da área cardíaca (ICT: 0,78$)$ às custas principalmente do arco inferior direito por dilatação exagerada do átrio direito. A ponta cardíaca é elevada pela dilatação do ventrículo direito e a trama vascular pulmonaré normal (fig. 1).

Impressão diagnóstica - É esta imagem sugestiva de cardiopatia? O aumento das cavidades cardíacas direitas e com trama vascular pulmonar normal sugere presença de insuficiência tricúspide, por alguma malformação congênita. A dilatação incomum do átrio direito em relação à do ventrículo direito pode sugerir a hipótese de aneurisma idiopático da cavidade atrial ou ainda malformação ventricular com diminuição do enchimento diastólico, por endomiocardiopatias restritivas.

Editor da Seção: Edmar Atik

Correspondência: Edmar Atik - InCor - Av. Dr. Enéas C. Aguiar, 44 - 05403-000 São Paulo, SP - E-mail: conatik@incor.usp.br

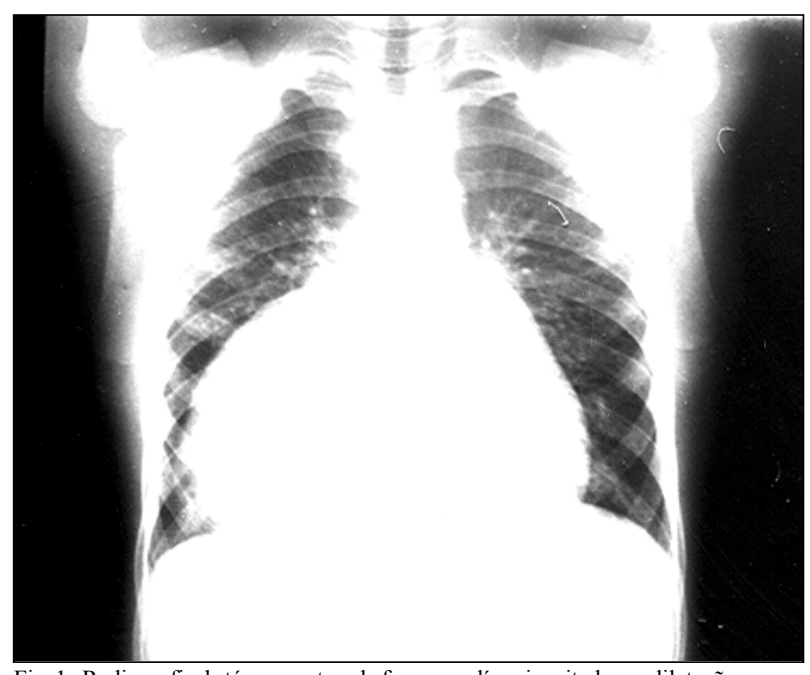

Fig. 1 - Radiografia de tórax mostrando forma cardíaca inusitada por dilatação exagerada da cavidade atrial direita.

Diagnóstico diferencial - A anomalia de Ebstein deve ser sempre lembrada em face de grande cardiomegalia, principalmente do átrio direito. Outras causas decorreriam de malformações valvares tricúspides, como displasias, prolapsos, agenesia parcial ou total ou ainda endocardite prévia com acometimento do tecido valvar e subvalvar.

Confirmação diagnóstica - $\mathrm{O}$ ecocardiograma salientou aumento desproporcional do átrio direito em relação a do ventrículo direito. A área da cavidade atrial era de $40 \mathrm{~cm} 2$ e a do ventrículo de $17 \mathrm{~cm}^{2}$. O anel tricúspide correspondeu a $38 \mathrm{~mm}$ e o anel da valva mitral a $24 \mathrm{~mm}$. O diâmetro diastólico do ventrículo direito era de $24 \mathrm{~mm}$ e do ventrículo esquerdo de $36 \mathrm{~mm}$.O débito pulmonar $(3,1 \mathrm{l} / \mathrm{mim})$ foi ligeiramente menor que o sistêmico $(3,41 / \mathrm{min})$ por discreto shunt da direita para a esquerda pelo forame oval. A função de ambos os ventrículos era normal. Foi sugerido diagnóstico de aneurisma idiopático de átrio direito, com insuficiência tricúspide secundária à dilatação do anel tricúspide.

Conduta - Indicou-se repetição do ato operatório prévio com técnicas de diminuição da cavidade atrial direita e da insuficiência tricúspide, a fim de se prevenir fenômenos congestivos e elétricos adversos. 